\title{
Utilization of Lasers in Modern Dental Practice
}

\section{Veenadevi Thonthula ${ }^{1}$, Thulasi Atchi' ${ }^{2}$, Krishna Madhukumaran Pillai Sreekaladevi $^{3 *}$, Shreya Kothari ${ }^{4}$, Hridya Jayaprakash ${ }^{5}$ and Divya Sudhakar ${ }^{6}$}

${ }^{1} 313$ Orchards Boulevard SW, Edmonton AB T6X1Y9, Canada

${ }^{2}$ Allen, Texas, USA

${ }^{3}$ Ex-Post Graduate, Department of Oral Medicine and Maxillofacial Radiology, KVG

Dental College and Hospital, Sulliya, India

${ }^{4}$ Emory University, Atlanta, Georgia, USA

${ }^{5}$ Periodontist, Clove Dental, Sholinganallur, Chennai, Tamil Nadu, India

${ }^{6}$ General Dentist, Masthan Dental Hospital, KK Nagar, Chennai, Tamil Nadu, India

*Corresponding Author: Krishna Madhukumaran Pillai Sreekaladevi, Ex-Post

Graduate, Department of Oral Medicine and Maxillofacial Radiology, KVG Dental Col-

lege and Hospital, Sulliya, India.
Received: December 21, 2021

Published: December 31, 2021

(C) All rights are reserved by Krishna

Madhukumaran Pillai Sreekaladevi., et al.

\begin{abstract}
LASER is an acronym of Light Amplification by the Stimulated Emission of Radiation. Technological advancements have maximized popularity and access to laser use with increased patient expectations for painless and noninvasive procedures. In recent years, laser has spread their applications from diagnosis to preventive procedures, making them an efficient and valuable tool for dental surgeon in near future. This article summarizes evidence-based published studies on the applications of lasers in current day's clinical practice in dentistry.
\end{abstract}

Keywords: Laser; Radiation; Light Amplification

\section{Introduction}

The term Laser is an acronym for 'Light Amplification by the Stimulated Emission of Radiation'. Since its introduction in Dentistry from1960s, it has attracted a lot of clinicians and researchers. The painless and bloodless nature of laser has gained a variety of applications in dentistry. Lasers in various soft tissue and hard tissue applications are considered by dental practitioners [1]. Based on the laser's nature of interaction with oral tissues, it has been used as an adjunctive aid in dentistry.
Brief history of lasers [2,3]:

- In 1917, Albert Einstein theorized photoelectric amplification which forms the base for laser technology.

- In the 1960s Nd: YAG (neodymium treated with yttrium-aluminum-garnet) was developed for dental hard tissue application.

- $\quad$ Argon laser was developed in 1962.

- Ruby laser is the first type of laser used for the coagulation of tissues. 
- $\quad$ Following this, in the 1970s CO2 laser was introduced for dental application.

Applications in dentistry

Soft tissue applications:

- Wound healing: Laser has its effect on the maturation and migration of fibroblasts which greatly affects the tensile strength of wounds. At low doses, it stimulates cell proliferation whereas at high doses it is suppressive. Low-level laser treatment (LLLT) induces myofibroblast transformation as soon as 24 hours of laser therapy. LLLT has been used in recurrent apthous stomatitis, after pulpotomy, mucositis, and oropharyngeal ulceration in patients undertaking radiotherapy for head and neck cancer [4].

- $\quad$ Frenectomy: The aberrant labial frenum is often associated with midline diastema and is indicated for frenectomy. Laser-assisted frenectomy is a simple procedure that is usually done after the closure of diastema. Aberrant lingual frenum leads to functional difficulties such as speaking difficulty, swallowing issues. Laser-assisted frenectomy is preferred nowadays as it is a painless, bloodless procedure and doesn't require suturing or surgical packs [5]. Post-operative care with laser frenectomy is simple and patient-friendly.

- Apthous ulcer: Photostimulation of laser therapy in apthous ulcer and herpes labialis provides symptomatic relief from pain and promotes healing [6]. Treatment with laser during prodromal stages seems to arrest vesicle formation and thereby accelerates the healing process. It also reduces the recurrence rate of lesions.

- Photoactivated dye disinfection: Lasers at low power mode are used for photochemical activation of oxygen-releasing dyes. This causes membrane and DNA destruction of microorganisms. The photoactivated dye (PAD) technique employs the use of visible red semiconductor diode lasers and toluidine blue dye. This technique is known to be effective against bacterial colonies in dental biofilm which are strongly resistant to antibiotics. This procedure can be applied effectively for the destruction of Gram-positive bacteria (including Methicillin-resistant Staphylococcus aureus (MRSA)), Gram-negative bacteria, fungi, and viruses [7]. It has been used in periodontitis, root canal therapy, deep caries, and peri-implantitis.
- Gingivectomy and Tissue removal: Conventional gingivectomy using a scalpel is not preferred nowadays as it leads to bleeding during the procedure and postoperative discomfort. With the advent of lasers in the past few decades, the laser is preferred for gingivectomy both by patients and dental professionals. Diode laser is the laser of choice for such procedures. Diode lasers are well absorbed by pigmented tissues and are deep penetrating, controlling hemostasis. Laser gingivectomy is indicated for exposure of crown for orthodontic procedures such as placement of molar band and brackets. Diode lasers are used in the depigmentation of gingiva for esthetic purposes [8]. Hypertrophic tissue could be gently excised using lasers. It is also indicated in the removal of tissue overgrown around brackets, implants, and impacted third molars.

- $\quad$ Photodynamic therapy (PDT): PDT has been indicated in the management of malignancies such as multi-focal squamous cell carcinoma. It works in the same principle as PAD. It produces reactive oxygen species which causes destruction of cells and the vascular unit, eventually resulting in cell death and necrosis. This, in turn, stimulates the host immune response and induces immunity against malignant cells via activating macrophages and $\mathrm{T}$ lymphocytes. Current evidence shows that tumor necrosis factor-alpha (TNF-a) is activated via PDT. TNF-a is a prominent cytokine meant for host immune activity. Research studies have demonstrated good results for the PDT treatment of carcinoma-in-situ and squamous cell carcinoma of the oral cavity, with positive response rates being $90 \%$ approximately [9].

Hard tissue application

- Cavity preparation: Er: YAG laser has been used in caries removal and cavity preparation around enamel and dentin without causing any detrimental effect on pulp. Caries removal using a laser doesn't require a water coolant system. It is similar to air-rotor devices but the floor of the cavity preparation is not found to be as smooth as conventional preparation. Caries removal and tooth preparation can be done using an erbium laser [10]. It protects the sound tooth structure while interacting with the diseased tissue. The Er: YAG laser is known to remove glass ionomer cement and composite resin from the tooth surface. 
- $\quad$ Photochemical effect: High-intensity light from argon laser initiates polymerization of light cured dental materials using camphoroquinone as a photoinitiator. The laser light energy from argon laser alters the microstructure of enamel and dentin surface and reduces the recurrence rate of caries. Vargas., et al. stated that argon laser can result in rapid polymerization of the composite when compared with conventional visible lights [11]. The bleaching effect depends on the absorption of green light results in the chelation of compounds such as apatite's, porphyrins. Argon and Potassium Titanyl Phosphate (KTiOPO4, KTP) lasers can produce better results in cases that are completely unresponsive to conventional photothermal 'power' bleaching.

- $\quad$ Etching: Erbium laser has been used in the etching of tooth structures as an alternative to conventional etching. However, the quality of etching seems to be inferior to conventional etching [12].

- Dentinal Hypersensitivity: Desensitizing agents are commonly used for hypersensitivity of dentin. Er: YAG laser has been recently researched for the management of dentinal hypersensitivity. The results of the clinical research show better results for laser therapy than conventional therapy. In addition, the results with laser treatment seem to give positive results for a longer period of time [13].

- $\quad$ E-model Preparation: Scanning of dental tissues with a laser creates a 3D model of dental structures. This makes the working environment easier for the dental professional team as it avoids the use of dental cast preparation. It also helps in educating the patient about the dental problems they have. These e-models are better for the storage of patient historyrelated details than conventional storage methods [14].

Other uses [15]:

- $\quad$ Successful analgesia following oral surgical procedures can be achieved with LLLT. Pain following orthodontic procedures could also be reduced by LLLT. A single episode of LLLT (irradiance $0.9-2.7 \mathrm{~J}$ ) is $100 \%$ effective in cases of apical periodontitis following root canal therapy and post-extraction pain.

- $\quad$ LLLT reduces the production of inflammatory mediators of the arachidonic acid family from injured nerves and pro- motes nerve maturation and regeneration following neuronal injury.

- $\quad$ Laser is found to be effective in regulating facial growth and could be a substitute for conventional methods such as a chin-cup.

\section{Conclusion}

Lasers are considered a much-needed advancement in the present day's world. Laser-based technology promises a better future in dentistry in terms of diagnosis and management of oral diseases. It is highly expected that lasers will contribute to most dental practices all around the world mainly due to their minimally invasive approach. The significant contribution of lasers in modern dental practice has served as an adjunct to conventional dental procedures. Further studies are required to further evaluate the beneficial effects of lasers since laser usage has taken a rapid growth in this advanced technological era.

\section{Bibliography}

1. Frentzen M and Koort HJ. "Lasers in dentistry: New possibilities with advancing laser technology". International Dental Journal 40.6 (1990): 323-332.

2. Maiman TH. "Stimulated optical radiation in ruby lasers". $N a-$ ture 187 (1960): 493.

3. Gross AJ and Hermann TR. "History of lasers". World Journal of Urology 25.3 (2007): 217-220.

4. Loevschall H and Arenholtd-Bindslev D. "Effect of low level diode laser irradiation of human oral mucosa fibroblasts in vitro". Lasers in Surgery and Medicine 14.4 (1994): 347-354.

5. Olivi G., et al. "Evidence-based dentistry on laser paediatric dentistry". European Journal of Paediatric Dentistry 10.1 (2009): 29-40.

6. Hargate G. "A randomized double-blind study comparing the effect of 1072-nm light against placebo for the treatment of herpes labialis". Clinical and Experimental Dermatology 31.5 (2006): 638-641.

7. O’Neill JF., et al. “Oral bacteria in multi-species biofilms can be killed by red light in the presence of toluidine blue". Lasers in Surgery and Medicine 31.2 (2002): 86-90. 
8. Sarver DM and Yanosky M. "Principles of cosmetic dentistry in orthodontics: Part 2. Soft tissue laser technology and cosmetic gingival contouring". American Journal of Orthodontics and Dentofacial Orthopedics 127.1 (2005): 85-90.

9. Biel MA. "Photodynamic therapy and the treatment of head and neck neoplasia”. Laryngoscope (1998): 1259-1268.

10. Burkes EJ, et al. "Wet versus dry enamel ablation by Er: YAG laser". Journal of Prosthetic Dentistry 67.6 (1992): 847-851.

11. Fleming MG and Maillet WA. "Photopolymerization of composite resin using the argon laser". Journal of Canadian Dental Association 65.8 (1999): 447-450.

12. Martinez-Insua A., et al. "Differences in bonding to acid-etched or Er: YAG-laser-treated enamel and dentine surfaces". Journal of Prosthetic Dentistry 84.3 (2000): 280-288.

13. Schwarz F., et al. "Desensitising effects of an Er:YAG laser on hypersensitive dentine, a controlled, prospective clinical study". Journal of Clinical Periodontology 29.3 (2002): 211-215.

14. Nute SJ and Moss JP. "Three-dimensional facial growth studied by optical surface scanning". Journal of Orthodontics 27.1 (2000): 31-38.

15. Verma SK., et al. "Laser in dentistry: An innovative tool in modern dental practice”. National Journal of Maxillofacial Surgery 3.2 (2012): 124-132.

\section{Assets from publication with us}

- Prompt Acknowledgement after receiving the article

- Thorough Double blinded peer review

- Rapid Publication

- Issue of Publication Certificate

- High visibility of your Published work

Website: www.actascientific.com/

Submit Article: www.actascientific.com/submission.php

Email us: editor@actascientific.com

Contact us: +919182824667

Citation: Krishna Madhukumaran Pillai Sreekaladevi., et al. "Utilization of Lasers in Modern Dental Practice". Acta Scientific Dental Sciences 6.1 (2022): 130-133. 